\title{
Inherited Selenocysteine Transfer RNA Mutation: Clinical and Hormonal Evaluation of 2 Patients
}

\author{
Aurore Geslot $^{\mathrm{a}} \quad$ Frédérique Savagner $^{\mathrm{b}} \quad$ Philippe Caron $^{\mathrm{a}}$ \\ aDepartment of Endocrinology and metabolic diseases, CHU Larrey, Toulouse, France; baboratory of Biochemistry, \\ CHU Purpan, Toulouse, France
}

\section{Established Facts}

- In 2016, a study [J Clin Invest. 2016 Mar;126(3):992-6] reported an 8-year-old male patient with multisystem symptoms, euthyroid hyperthyroxinemia, selenium deficiency, and germinal homozygous mutation in the TRU-TCA1-1 gene, encoding tRNA ${ }^{[\mathrm{Ser}] \mathrm{Sec}}$.

\section{Novel Insights}

- We report 2 members of a family with the variant in the C65G TRU-TCA1-1 gene, encoding tRNA ${ }^{[\mathrm{Ser}] \mathrm{Sec}}$ :

- The homozygous index case presented a euthyroid hyperthyroxinemia, and his heterozygous father had normal thyroid function tests.

- In both patients, the expression of stress-related selenoprotein GPX3 and metalloprotein SOD was decreased.

\section{Keywords}

Selenoproteins - Deiodinases - TRU-TCA1-1 gene · Euthyroid hyperthyroxinemia · Transfer RNA mutation

\begin{abstract}
Introduction: lodothyronine deiodinases are selenoproteins with the amino acid selenocysteine ( $\mathrm{Sec}$ ) introduced into the position of a TGA stop codon by a complex machinery involving $\mathrm{tRNA}^{[\mathrm{Ser}] \mathrm{Sec}}$ when a cis-acting Sec-insertion sequence element is present in the $3^{\prime}$ end of the mRNA. Recently, a variant in the TRU-TCA1-1 gene encoding for tRNA ${ }^{[\mathrm{Ser}] \mathrm{Sec}}$ was reported, which resulted in reduced expression of stress-related selenoproteins. The proband presented with multisys-
\end{abstract}

tem symptoms, euthyroid hyperthyroxinemia, and selenium deficiency. Here, we describe 2 new members of a family harboring the same tRNA ${ }^{[\mathrm{Ser}] \mathrm{Sec}}$ variant. Case Presentation: A 13-year-old patient was seen for Hashimoto's disease with high FT3 (4.6 pg/mL, normal range $2-4.2 \mathrm{pg} / \mathrm{mL}$ ) and normal FT4 and TSH concentrations. He had no clinical complaints. During a 6-year clinical and hormonal follow-up, the index patient was not treated, FT3 decreased, FT4 increased, and serum TSH stayed in the normal range resulting in a euthyroid hyperthyroxinemia. Reverse T3 concentration was significantly increased at the last visit (19 years and 4 months). At the last evaluation, the total selenium level was low (91 $\mu \mathrm{g} / \mathrm{L}$, normal range 95-125). DNA sequencing identified a germinal homozygous variant (C65G) in the TRU-TCA1-1
Correspondence to:

Philippe Caron, caron.p@ chu-toulouse.fr 
gene. During follow-up, no additional clinical symptom was observed in the absence of any treatment. The same germinal tRNA ${ }^{[\mathrm{Ser}] \mathrm{Sec}}$ variant was identified at heterozygous state in his father, who had normal thyroid function tests except a moderately increased reverse T3 concentration, with increased total selenium ( $143 \mu \mathrm{g} / \mathrm{L}$ ) level. In both patients, the expression of stress-related selenoprotein GPX3 was in the low-normal range (168 and $180 \mathrm{IU} / \mathrm{L}$, respectively, normal range: $150-558 \mathrm{IU} / \mathrm{L})$. We did not find any significant biological abnormalities evocative of other selenoprotein deficiencies. Discussion/Conclusion: We report on 2 members of a family with a variant in the TRU-TCA1-1 gene encoding for tRNA ${ }^{[\mathrm{Ser}] \mathrm{Sec}}$. Our study suggests that this tRNA ${ }^{[\mathrm{Ser}] \mathrm{Sec}}$ variant is not exclusively causative of disruption in selenoprotein synthesis.

(C) 2021 European Thyroid Association Published by S. Karger AG, Basel

\section{Introduction}

Selenium is a trace element incorporated in some proteins as selenocysteine ( $\mathrm{Sec}$ ). The group of selenoproteins includes deiodinases. In cases of selenium deficiency, some selenoprotein activities decrease, depending on organs and tissues. For example, in the liver and kidneys, type-1 deiodinase expression decreases but is maintained in thyroid tissue $[1,2]$.

Selenoprotein synthesis requires selenocysteine-specific tRNA (Sec-tRNA ${ }^{[\mathrm{Ser}] \mathrm{Sec}}$ ), able to specifically decode the stop codon UGA to insert Sec into proteins. Synthesis of Sec occurs on tRNA ${ }^{[\mathrm{Ser}] \mathrm{Sec}}$ : first, serine ties to tRNA $^{[\mathrm{Ser}] \mathrm{Sec}}$ and is then phosphorylated to accept selenophosphate and becomes Sec-tRNA ${ }^{[\mathrm{Ser}] \mathrm{Sec}}$. SectRNA $^{[\text {Ser]Sec }}$ undergoes maturation with sequential base modifications, yielding 2 major tRNA ${ }^{[\mathrm{Ser}] \mathrm{Sec}}$ isoforms containing either 5-methoxycarbonyl-methyluridine (mc$\mathrm{m}^{5} \mathrm{U}$ ) or 5-methoxycarbonylmethyl-2'-O-methyluridine $\left(\mathrm{mcm}^{5} \mathrm{Um}\right)$ at position 34 . A multiprotein complex, including EEFSEC and SECISBP2, recruits Sec-tRNA ${ }^{[\mathrm{Ser}] \mathrm{Sec}}$ to the SECIS stem loop element located in the $3^{\prime}$-UTR of selenoprotein mRNAs. Thereby, ribosome can incorporate Sec in selenoproteins using the UGA codon [3-5].

Mutations in the SECISBP2 gene have been described in humans, with reduced synthesis of selenoproteins, resulting in a multisystemic phenotype including azoospermia, axial muscular dystrophy, cutaneous photosensitivity, impaired T-cell proliferation and abnormal cytokine production, increased fat mass, and enhanced insulin sensitivity, as well as hearing loss and abnormal thyroid function tests (elevated free T4 levels and normal levels of free T3 and TSH). For these patients, selenium levels were low, and selenium supplementation failed to correct defective selenoprotein synthesis [6-9].

In 2016, Schoenmakers et al. [5] described an 8-yearold male patient presenting symptoms that can be evocative of SECISBP2 anomalies including thyroid dysfunction and low selenium plasma level. The SECISBP2 variantwasnotfound, andexpression profilesofselenoproteins were different from those of patients with SECISBP2 mutations. Indeed, housekeeping selenoprotein synthesis was preserved in the proband compared to patients with SECISBP2 mutations instead of stress-related selenoproteins, whose expression was similarly reduced. In this patient with parental consanguinity, they found an unknown germinal homozygous mutation in the TRUTCA 1-1 gene, encoding tRNA ${ }^{[\mathrm{Ser}] \mathrm{Sec}}$. His parents and one of his brothers had the same mutation, but were heterozygous and asymptomatic, with normal thyroid function and selenium level. This mutation may increase turnover of mutant tRNA and impede base modifications essential to tRNA ${ }^{[\mathrm{Ser}] \mathrm{Sec}}$ maturation $[5,10,11]$. They also identified reduced levels of transcript and $\mathrm{mcm}^{5} \mathrm{Um}$ isoforms. Systemic selenium status influences relative proportion of isoforms $[12,13]$. Thus, methylation depends on selenium level, and the $\mathrm{mcm}^{5} \mathrm{Um}$ isoform is poorly expressed in selenium deficiency. Indeed, Kim et al. [11] suggested that methylation requires $\mathrm{Sec}$ to occur. This isoform is especially necessary for the synthesis of stress-related selenoproteins [5]. Here, we describe 2 new patients of a family harboring the same tRNA ${ }^{[\mathrm{Ser}] \mathrm{Sec}}$ variant $(\mathrm{C} 65 \mathrm{G})$.

\section{Case Report}

Patients

A 10-year-old patient consulted for Hashimoto's disease with clinical euthyroidism. In thyroid function tests, FT3 was increased (4.6 pg/mL, normal range $2-4.2 \mathrm{pg} / \mathrm{mL}$ ), and FT4 and TSH concentrations were normal. Polyethylene-glycol precipitation allowed us to eliminate the presence of anti-T3 antibodies to explain the increased FT3 concentration. In an ultrasound scan, the thyroid gland was hypertrophic but homogeneous. The father suffered from hemorrhagic recto-colitis and had a heart attack at the age of 41 years, without cardiovascular risk factor.

\section{Methods}

Thyroid Function Tests

Serum TSH, fT3, and fT4 levels were measured with kits routinely used in the Biochemistry Department of our hospital (ElectroChemiLuminescence Immunosorbent Assay; Roche Diagnostics, Mannheim, Germany). Reverse T3 was measured by competitive RIA (Diasource, Louvain La Neuve, Belgium). 
Table 1. Concentrations of TSH, FT4, and FT3 in the index patient between 2010 and 2016

\begin{tabular}{llll}
\hline Age of the index patient & $\begin{array}{l}\text { TSH } \\
(0.4-4.4 \mu \mathrm{U} / \mathrm{mL})\end{array}$ & $\begin{array}{l}\text { FT4 } \\
(7.5-16 \mathrm{pg} / \mathrm{mL})\end{array}$ & $\begin{array}{l}\text { FT3 } \\
(2.0-4.2 \mathrm{pg} / \mathrm{mL})\end{array}$ \\
\hline 13 years and 3 months & 2.16 & Normal & $\mathbf{4 . 6}$ \\
14 years & 2.30 & $\mathbf{1 6 . 9}$ & $\mathbf{4 . 9}$ \\
14 years and 5 months & 2.0 & 15.7 & $\mathbf{4 . 8}$ \\
15 years and 5 months & 2.40 & $\mathbf{1 7 . 1}$ & $\mathbf{4 . 1}$ \\
16 years & 1.70 & $\mathbf{1 7 . 1}$ & $\mathbf{4 . 8}$ \\
17 years and 4 months & 2.90 & $\mathbf{1 8 . 1}$ & 3.5 \\
19 years & 2.0 & $\mathbf{2 0 . 1}$ & 3.9 \\
19 years and 4 months & 2.5 & $\mathbf{1 8 . 7}$ & 3.8 \\
\hline
\end{tabular}

Table 2. SNP genotypes in the $19 \mathrm{q} 13.32$ region including the TRU-TCA1-1 gene in our proband and his parents

\begin{tabular}{llllll}
\hline 19q13.32 $(44,729,208-45,911,752)$ & & & & \\
\hline dbSNP ID & $\begin{array}{l}\text { genomic } \\
\text { coordinate }\end{array}$ & $\begin{array}{l}\text { proband's } \\
\text { genotype }\end{array}$ & $\begin{array}{l}\text { father's } \\
\text { genotype }\end{array}$ & $\begin{array}{l}\text { mother's } \\
\text { genotype }\end{array}$ & conclusion \\
\hline rs10414420 & $45,911,752$ & CC & CT & TT & Paternal isodisomy \\
rs10406475 & $45,911,135$ & TT & TG & GG & Paternal isodisomy \\
rs1603 & $45,488,278$ & CC & CG & GG & Paternal isodisomy \\
rs7259949 & $45,478,699$ & CC & CC & GG & Paternal isodisomy \\
Variant 65 & $45,478,582$ & GG & CG & GC & Paternal isodisomy \\
rs7245548 & $45,478,557$ & GC & CA & GG & Noninformative \\
rs6509214 & $45,478,197$ & GG & GA & AA & Paternal isodisomy \\
rs8103655 & $45,044,897$ & GG & GA & AA & Paternal isodisomy \\
rs3786507 & $44,739,733$ & AA & AA & GG & Paternal isodisomy \\
rs2927439 & $44,729,208$ & AA & GA & GG & Paternal is origin \\
rs2965106 & & & & &
\end{tabular}

\section{Selenium Concentrations}

The total selenium concentration corresponds to whole blood selenium measured by inductively coupled plasma mass spectrometry (Nexion 350; Perkin Elmer, Waltham, MS, USA), and serum selenium was measured after centrifugation of the blood sample obtained on a dry tube. Serum selenium was also measured by inductively coupled plasma mass spectrometry.

\section{TRU-TCA1-1 Genotyping}

The patient's genomic DNA was extracted from a blood sample using the QIAcube apparatus and DNeasy blood extraction kit (all from Qiagen). The coding sequence of TRU-TCA1-1, including 2 polymorphisms located in the neighborhood of the coding region (rs7245548 and rs6509214), was amplified using 2 pairs of DNA primers: tRNAsecS1: 5'-CTGGGCCCTTTAACAGCTT-3'; tRNAsecR1: $5^{\prime}$-AGTTATGGTCGCGTCCTTTG- $3^{\prime}$ and tRNAsecF2: $\quad 5^{\prime}$-CACGATAAATGAGTGGGGAGA-3'; tRNAsecR2: $5^{\prime}$-CGGGCAACAAGCAAAATAAG-3', previously described by Schoenmakers et al. $[5,12]$. Sequences were analyzed on the ABI PRISM 3100 apparatus (Thermo Fisher). Extended analysis of single-nucleotide polymorphism (SNP) in the 19q13.32 region has been performed by the same sequencing method using primers described in complementary data (see online Supplementary Materials).

\section{Plasma GPX3 and SOD Assays}

Plasma GPX3 was quantified using glutathione reductase/ cumene hydroperoxide reaction (Glutathione Peroxidase Assay Kit; Clinisciences). NADPH consumption at $340 \mathrm{~nm}$ was proportional to glutathione oxide quantity, therefore to glutathione peroxidase activity $[5,14]$.

Plasma superoxide dismutase (SOD) levels were explored using a WST-1 substratum to product formazan during superoxide anion liberation (Superoxide Dismutase Activity Colorimetric Assay Kit; Clinisciences). Formazan consumption at $630 \mathrm{~nm}$ was proportional to the production of superoxide anion [15]. Assays were realized in triplicate for the patients and for 10 controls.

\section{Results}

\section{Thyroid Hormone Function Tests}

During a 6-year clinical and hormonal follow-up of the index patient, concentrations of FT3 decreased, FT4 increased, and serum TSH level stayed in the normal range resulting in an euthyroid hyperthyroxinemia (Table 1), such as that observed in the patient described by Schoen- 
Table 3. Blood level of GPX3 and SOD, 2 selenium-dependent enzymes in the index patient and his parents

\begin{tabular}{llllll}
\hline & $\begin{array}{l}\text { Index } \\
\text { patient }\end{array}$ & Father & Mother & Controls* & Normal range \\
\hline GPX3 & 168 & 180 & 252 & $338 \pm 35$ & $150-558 \mathrm{IU} / \mathrm{L}$ \\
SOD & 1.2 & 1.8 & 3.3 & $3.5 \pm 0.2$ & $2.2-6.7 \mathrm{U} / \mathrm{mL}$ \\
\hline
\end{tabular}

GPX3, glutathione peroxidase 3; SOD, superoxide dismutase. * Based on selenoprotein levels in 10 healthy patients.

makers et al. [5]. His father had a normal level of TSH (2.2 $\mu \mathrm{U} / \mathrm{mL}$, normal range $0.27-4.2 \mu \mathrm{U} / \mathrm{mL})$, FT4 $(15.0 \mathrm{pg} / \mathrm{mL}$, normal range $9.3-17 \mathrm{pg} / \mathrm{mL})$, and FT3 $(3.3 \mathrm{pg} / \mathrm{mL}$, normal range $2.0-4.4 \mathrm{pg} / \mathrm{mL})$ as did his mother $(\mathrm{TSH}=1.2 \mu \mathrm{U} / \mathrm{mL}$, FT4 $=16.3 \mathrm{pg} / \mathrm{mL}$, and FT3 $=3.5 \mathrm{pg} / \mathrm{mL}$ ). Serum reverse T3 concentration was significantly increased in the proband at 19 years and 4 months $(78 \mathrm{ng} / \mathrm{dL}$, normal range 11-39 ng/dL), moderately increased in the father (48 ng/ $\mathrm{dL})$, and in the normal range in the mother $(20.5 \mathrm{ng} / \mathrm{mL})$.

\section{Genetic Analysis}

The proband had no SECISBP2 mutation in the entire coding sequence. Genetic analysis identified a germinal variant in a single nucleotide (n.65C $>$ G or $\mathrm{C} 65 \mathrm{G}$ ) of the TRU-TCA1-1 gene as described by Schoenmakers et al. [5], homozygous for the proband and heterozygous for his father (Table 2). The proband has proved to present paternal uniparental disomy. His mother was free of the C65G variant. There was no parental consanguinity.

\section{Selenium Concentrations}

At the last visit at 19 years and 4 months old, the index patient had a low total selenium level: $91.1 \mu \mathrm{g} / \mathrm{L}$ (normal range: 95-125), but it was at the upper limit of normal range 6 months later $(128 \mu \mathrm{g} / \mathrm{L})$, whereas the serum selenium level was normal at 2 determinations $(91.6 \mu \mathrm{g} / \mathrm{L}$ and $97.4 \mu \mathrm{g} / \mathrm{L}$, normal range: 70-100). His father had increased total selenium (143 $\mu \mathrm{g} / \mathrm{L}$, normal range $89-134$ $\mu \mathrm{g} / \mathrm{L})$ and serum selenium $(115.8 \mu \mathrm{g} / \mathrm{L}$, normal range $79-$ $110 \mu \mathrm{g} / \mathrm{L})$ levels, whereas the mother had normal-high levels of serum selenium $(110.6 \mu \mathrm{g} / \mathrm{L})$ and total plasma selenium $(125 \mu \mathrm{g} / \mathrm{L})$.

\section{Plasma GPX3 and SOD Assays}

Expressions of stress-related selenoprotein (GPX3) and metalloprotein (SOD) were decreased: glutathione peroxidase 3 (GPX3) was in the low-normal range, 168 IU/L for the proband and $180 \mathrm{IU} / \mathrm{L}$ for the father (normal
Table 4. Results of biochemical, hematological, and immunological analyses for the proband and his father

\begin{tabular}{lrr}
\hline & Proband & Father \\
\hline Biochemistry & & \\
Fasting glucose $(0.74-1.06 \mathrm{~g} / \mathrm{L})$ & 0.81 & 0.83 \\
Cholesterol $(1.5-2.2 \mathrm{~g} / \mathrm{L})$ & 1.4 & 2.7 \\
Triglycerides $(0.5-1.5 \mathrm{~g} / \mathrm{L})$ & 0.9 & 1.6 \\
Hematology & & \\
Hemoglobin $(13-17.5 \mathrm{~g} / \mathrm{dL})$ & 15.5 & 16.7 \\
Leucocytes $(4-10 \mathrm{G} / \mathrm{L})$ & 6.6 & 4.9 \\
Lymphocytes $(1.5-4 \mathrm{G} / \mathrm{L})$ & 2.8 & 1.4 \\
Blood platelets $(150-450 \mathrm{G} / \mathrm{L})$ & 237 & 216 \\
Immunoglobulins & & \\
IgG $(5.5-15.8 \mathrm{~g} / \mathrm{L})$ & 12.4 & \\
IgA $(0.6-3.5 \mathrm{~g} / \mathrm{L})$ & 2.1 & \\
IgM $(0.2-2.6 \mathrm{~g} / \mathrm{L})$ & 1.6 & \\
Lymphocyte immunophenotyping & & \\
CD3+ $\left(700-2,800 / \mathrm{mm}^{3}\right)$ & 2,012 & \\
CD3+ CD4+ $\left(370-1,800 / \mathrm{mm}^{3}\right)$ & 842 & \\
CD3+ CD8+ $\left(120-800 / \mathrm{mm}^{3}\right)$ & 1,100 & \\
CD19+ $\left(60-600 / \mathrm{mm}^{3}\right)$ & 125 & \\
CD3- CD16/56+ $\left(50-500 / \mathrm{mm}^{3}\right)$ & 223 & \\
\hline
\end{tabular}

range: $150-558 \mathrm{IU} / \mathrm{L}$ ), and SOD was low, $1.2 \mathrm{U} / \mathrm{mL}$ for the proband and $1.8 \mathrm{U} / \mathrm{mL}$ for his father (normal range: 3.5 $\pm 0.2 \mathrm{U} / \mathrm{mL}$ ), compared to controls and the proband's mother levels (Table 3). Finally, levels of immunoglobulin and lymphocyte immunophenotyping were normal for the proband and his father (Table 4).

\section{Discussion}

We report here the presence of a C65G variant in the TRU-TCA1-1 gene, encoding for tRNA ${ }^{[\mathrm{Ser}] \mathrm{Sec}}$, in 2 members of a new family. The 2 male patients were clinically asymptomatic, but for the index case with homozygous mutation, follow-up of the thyroid function revealed the presence of euthyroid hyperthyroxinemia suggesting impaired deiodinase activity $[16,17]$.

During the follow-up of the proband between 13 and 19 years, TSH concentrations were in the normal range, FT4 levels increased from 13-14 years into adulthood, abnormal FT3 decreased from a peak at the age of 13 years, and rT3 concentration was abnormal at the last visit. Therefore, the dynamic of FT3 and FT4 levels in the proband from childhood into adolescence appears to be independent of the TRUT-TCA1-1 mutation and reflects the age-appropriate changes $[18,19]$. Independent of this rather normal dynamic, the absolute FT4 concentrations appeared indeed 
too high, consistent with the suggested euthyroid hyperthyroxinemia due to the Sec incorporation defect.

A low selenium level was compatible with selenium consumption due to excessive selenoprotein turnover [20] or most likely due to failure to incorporate Sec into selenoproteins. In the proband, insufficiency in food intake of selenium was unlikely as at the same time the parents had high selenium levels. As referred in the previous study [5], we have also shown that heterozygote mutation in one patient may not impair housekeeping selenoprotein synthesis and activity.

In our study, as for Schoenmakers et al. [5], stress-related selenoprotein GPX3 concentrations were decreased in the proband and his father, implying that this tRNA ${ }^{[S e r] S e c}$ mutation could impact selenoprotein synthesis and/or activity. SOD is a metalloprotein with different isoforms such as MnSOD in the mitochondrial compartment and CuZnSOD in the cytosolic compartment. As a major antioxidant system, SOD expression is dependent on selenoproteins involved in oxidative stress regulation such as GPX and TRX. It was reported that selenium treatment increased SOD and catalase activities [21]. On the other hand, decrease in selenium could have inverse effect leading to decrease in SOD expression. Close relationship between SOD and selenoproteins has been also proved as excess of $\mathrm{H}_{2} \mathrm{O}_{2}$ and SOD expression led to irreversible inactivation of selenocysteine [22]. Finally, influence of other trace elements could be suggested as SOD enzymes use manganese, copper, or zinc, but SOD activity was normal in the mother.

\section{Conclusion}

We hypothesize that patients with the C65G variant have a higher susceptibility to oxidative stress due to a lack of SOD/GPX activity, imbalance from T3 due to improper functioning from deiodinases, and possible other selenoproteins affected with unknown effect. Thus, ge- netic and dietary factors can affect the bioavailability of $\mathrm{Se}$ or Sec and the whole seleno-proteome [23, 24]. To determine the role of a SNP as a true risk factor, we should consider the complex relation between SNP and polygenic diseases [23].

\section{Statement of Ethics}

Written informed consent was initially obtained from the parents when the index case was evaluated at the age of 13 years and then from all 3 patients to publish their clinical, hormonal, and genetic data. The study is exempt from ethics committee approval as the patients are only followed without any treatment. The research was conducted ethically in accordance with the World Medical Association Declaration of Helsinki.

\section{Conflict of Interest Statement}

The authors declare that they have no conflicts of interest regarding the data reported in this article.

\section{Funding Sources}

The authors did not receive any specific grant for the preparation of data and the manuscript.

\section{Author Contributions}

A.G. and P.C. were responsible for collecting clinical data from the family. F.S. was responsible for collecting DNA data from the family. The first draft of the manuscript was written by A.G., and all authors commented on the previous version of the manuscript. All authors read and approved the final version of the manuscript.

\section{Data Availability Statement}

The authors confirm that the data supporting the findings of this study are available within the article and its supplementary materials.

\section{References}

1 Arthur JR, Bermano G, Mitchell JH, Hesketh JE. Regulation of selenoprotein gene expression and thyroid hormone metabolism. Biochem Soc Trans. 1996 May;24(2):384-8.

2 Drutel A, Archambeaud F, Caron P. Selenium and the thyroid gland: more good news for clinicians. Clin Endocrinol. 2013 Feb;78(2):155-64.

3 Shetty SP, Copeland PR. Selenocysteine incorporation: a trump card in the game of mRNA decay. Biochimie. 2015 Jul;114:97-101.
4 Labunskyy VM, Hatfield DL, Gladyshev VN. Selenoproteins: molecular pathways and physiological roles. Physiol Rev. 2014 Jul; 94(3):739-77.

5 Schoenmakers E, Carlson B, Agostini M, Moran C, Rajanayagam O, Bochukova E, et al. Mutation in human selenocysteine transfer RNA selectively disrupts selenoprotein synthesis. J Clin Invest. 2016 Mar;126(3): 992-6.
6 Schoenmakers E, Agostini M, Mitchell C, Schoenmakers N, Papp L, Rajanayagam O, et al. Mutations in the selenocysteine insertion sequence-binding protein 2 gene lead to a multisystem selenoprotein deficiency disorder in humans. J Clin Invest. 2010 Dec;120(12):4220-35.

7 Fradejas-Villar N. Consequences of mutations and inborn errors of selenoprotein biosynthesis and functions. Free Radic Biol Med. 2018 Nov;127:206-14. 
8 Di Cosmo C, McLellan N, Liao XH, Khanna KK, Weiss RE, Papp L, et al. Clinical and molecular characterization of a novel selenocysteine insertion sequence-binding protein 2 (SBP2) gene mutation (R128X). J Clin Endocrinol Metab. 2009 Oct;94(10):4003-9.

9 Schomburg L, Dumitrescu AM, Liao XH, BinAbbas B, Hoeflich J, Köhrle J, et al. Selenium supplementation fails to correct the selenoprotein synthesis defect in subjects with SBP2 gene mutations. Thyroid. 2009 Mar; 19(3):277-81.

10 Kim LK, Matsufuji T, Matsufuji S, Carlson BA, Kim SS, Hatfield DL, et al. Methylation of the ribosyl moiety at position 34 of selenocysteine tRNA[Ser]Sec is governed by both primary and tertiary structure. RNA. 2000 Sep; 6(9):1306-15.

11 Kim JY, Carlson BA, Xu XM, Zeng Y, Chen S, Gladyshev VN, et al. Inhibition of selenocysteine tRNA[Ser]Sec aminoacylation provides evidence that aminoacylation is required for regulatory methylation of this tRNA. Biochem Biophys Res Commun. 2011 Jun; 409(4):814-9.

12 Hatfield D, Lee BJ, Hampton L, Diamond AM. Selenium induces changes in the selenocysteine tRNA[Ser]Sec population in mammalian cells. Nucleic Acids Res. 1991 Feb; 19(4):939-43.
13 Diamond AM, Choi IS, Crain PF, Hashizume T, Pomerantz SC, Cruz R, et al. Dietary selenium affects methylation of the wobble nucleoside in the anticodon of selenocysteine tRNA([Ser]Sec). J Biol Chem. 1993 Jul; 268(19):14215-23.

14 Schoenmakers E, Chatterjee K. Identification of genetic disorders causing disruption of selenoprotein biosynthesis. Methods Mol Biol. 2018;1661:325-35.

15 Peskin AV, Winterbourn CC. A microtiter plate assay for superoxide dismutase using a water-soluble tetrazolium salt (WST-1). Clin Chim Acta. 2000 Mar;293(1-2):157-66.

16 Dumitrescu AM, Liao XH, Abdullah MS, Lado-Abeal J, Majed FA, Moeller LC, et al. Mutations in SECISBP2 result in abnormal thyroid hormone metabolism. Nat Genet. 2005 Nov;37(11):1247-52.

17 Germain DL, Hernandez A, Schneider MJ, Galton VA. Insights into the role of deiodinases from studies of genetically modified animals. Thyroid. 2005 Aug;15(8):905-16.

18 Taylor PN, Sayers A, Okosieme O, Das G, Draman MS, Tabasum A, et al. Maturation in serum thyroid function parameters over childhood and puberty: results of a Longitudinal Study. J Clin Endocrinol Metab. 2017 Jul;102(7):2508-15.
19 Marwaha RK, Tandon N, Desai AK, Kanwar R, Sastry A, Narang A, et al. The evolution of thyroid function with puberty. Clin Endocrinol. 2012 Jun;76(6):899-904.

20 Tobe R, Mihara H. Delivery of selenium to selenophosphate synthetase for selenoprotein biosynthesis. Biochim Biophys Acta Gen Subj. 2018 Jun;1862(18):2433-40.

21 Zhu K, Jiang L, Chu Y, Zhang YS. Protective effect of selenium against cisplatin-induced nasopharyngeal cancer in male albino rats. Oncol Lett. 2016 Dec;12(6):5068-74.

22 Woo HA, Yim SH, Shin DH, Kang D, Yu DY, Rhee SG. Inactivation of peroxiredoxin I by phosphorylation allows localized $\mathrm{H}(2) \mathrm{O}(2)$ accumulation for cell signaling. Cell. $2010 \mathrm{Feb}$ 19;140(4):517-28.

23 Méplan C. Association of single nucleotide polymorphisms in selenoprotein genes with cancer risk. Methods Mol Biol. 2018;1661: 313-24.

24 Guo L, Yang W, Huang Q, Qiang J, Hart JR, Wang W, et al. Selenocysteine-specific mass spectrometry reveals tissue-distinct selenoproteomes and candidate selenoproteins. Cell Chem Biol. 2018 Nov;25(11):1380-8. e4. 